\title{
Comparison between symptoms of COVID-19 and other respiratory diseases
}

\author{
Sukaina Rahman Neamah ${ }^{1 *}$ \\ ${ }^{1}$ General Directorate of Education in Thi-Qar , Ministry of Education, Iraq \\ * Corresponding author: Sukaina Rahman Neamah E-mail: sukainarn2@gmail.com ORCID: 0000-0002-2897-2675 \\ Received: 27 May 2020 Accepted: 19 July 2020
}

\begin{abstract}
The ability to perceive the principle symptoms of COVID-19 is very critical as to diminish and control disease in a suitable time. There are numerous similar symptoms of cold, influenza, hypersensitivities and novel coronavirus. The greatest difference is the brevity of breath related with COVID-19. This flu virus or cold does not cause brevity of breath except if it advances to pneumonia. Different symptoms of COVID-19 are fever and coughing dry, extended to incorporate chills, loss of taste and smell, ache of muscle and head and sore throat. A cold, incorporate sneezing, cough, stodgy nose. It clears up within few period by itself. Influenza, incorporate fever or hot/chills, ache of muscle and head and runny nose. It can prompt genuine complications, e.g. pneumonia and death. Sensitivity symptoms are hypersensitivities, irritated eyes, sneezing and nasal runny relying upon the season and environment. In spite of overlap, the regular symptoms of COVID-19 are more like influenza than the normal cold or sensitivity. Individuals at home can be able to treat mild COVID-19 symptoms. On the off chance that they notice increasingly severe indications. In case of serious symptoms, an individual should look for medical assistance right away and inform the health care insurance supplier that they may have COVID-19, to assist them with avoiding potential risk as well as take the appropriate safety. It is important to bear in mind that the correct diagnosis of COVID-19 is not clinical, but rather by examining a sample from the nose or mouth in a laboratory.
\end{abstract}

Keywords: SARS, flu, COVID-19, Wuhan, symptom

\section{INTRODUCTION}

Corona viruses are a wide gathering of viruses that causes human disease or animals. Several corona viruses in humans cause respiratory infection, varying from the regular common cold to more serious illnesses, for example, MERS (Middle East Respiratory Syndrome) and SARS [Acute Respiratory Syndrome]. The most recent coronavirus detected triggers corona-infection COVID-19. COVID-19 Pandemic proceeds from the 2019 coronavirus brought about by serious intense respiratory syndrome SARS-CoV-2 [1]. The epidemic had first been recognized in Wuhan, China, early December 2019 [2]. The virus then dispersed to nearly each country, where on 30 January the World Health Organization reported the outbreak to be an immediate public health crisis and on 11 March an epidemic. The virus was first passed to humans by animals, in which the first individual - COVID-19 had ties to the meat and seafood industry. The disease was then established by people without consumer touch, which affirms that people can 


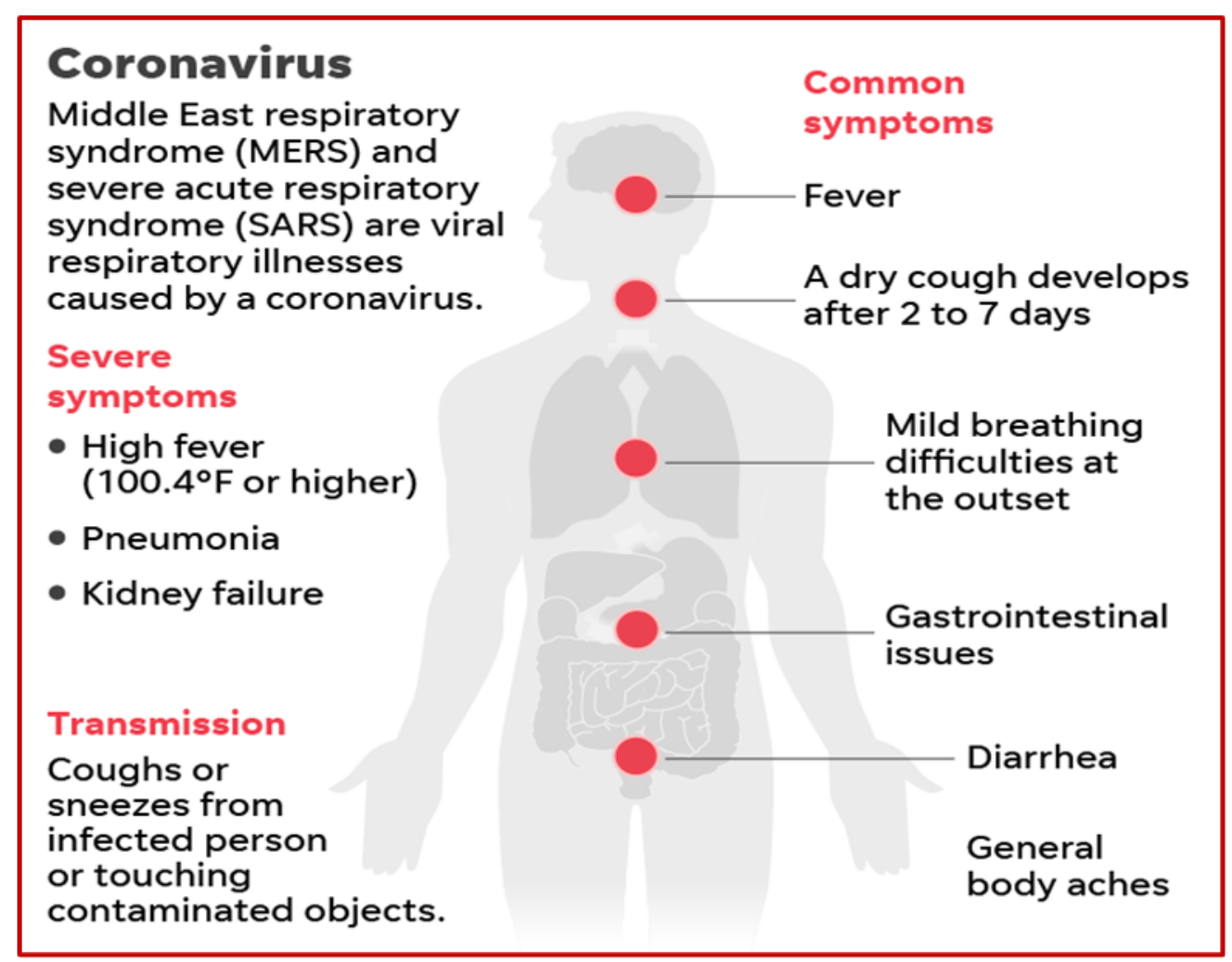

Figure 1. Symptoms of COVID-19

transmit the infection between them $[3,4]$. The modern corona-virus was liable for many diseases around the world, causing countless deaths, with the biggest number of these passing in the United States. The epidemic has led to serious global social and economic disturbance, just as the delay or crossing out of sporting, strict, political and social occasions, and the closure of schools, universities and colleges at national or local level in 190 countries, affecting almost 73.5 percent of students worldwide [5].

\section{Incubation Period}

It is estimated that the incubation time of COVID-19 ranges from 2-14 days, with an average duration about 4 to 5 days after introduction of indications. One study reported that $97.5 \%$ of people with symptoms of COVID-19 would do so within 11 days of infection with SARS-CoV-2 [6,7].

\section{Severity of the Disease}

The largest group of more than 44,000 Chinese infected by COVID-19 people found that the prevalence of the disease has risen from moderate to severe: mild to moderate $81 \%$, acute $14 \%$ and critical 5\% [8]. Serious pneumonia, intense heart injury and less cases of renal failure were the major pathogenesis of COVID-19 infection as a respiratory system targeting virus $[9,10]$. SARS-CoV-2 infection causes what is termed a cytokine storm by interleukin 6 (IL-6) creation which causes an enormous inflammatory reaction in the lung epithelial tissues. In addition, viral replication contributes to cell damage that discharges acute phase protein (thermoregulation) to increase the body's heat level [10-13]. It is important to understand the viral structure and genome of the SARS-CoV-2 pathogenesis mechanisms. Figure 3 shows SARS-CoV-2 life cycle in host cells [11,14-16].

\section{Symptoms Common of Coronavirus}

COVID-19 affects different people in different ways, as symptoms of a cold or flu appear within 2-4 days after the infection develops. Most people undergo mellow to moderate sickness and recoup without hospitalization. In some cases, coronavirus infection is fatal. Anyone with moderate and stable symptoms should monitor their signs at household [17].

\section{The most common symptoms include}

Fever $83-99 \%$, cough $59-82 \%$, loss of appetite $40-84 \%$, fatigue $44-70 \%$, dyspnea $31-40 \%$, sputum production 28 $33 \%$, muscle pain $11-35 \%$ and fatigue $[2,7,8,17-20]$.

Less common symptoms that can cause certain patients include soreness, nasal irritation, headaches, eye infections, sore throat, loss of sensation or scent, skin rash, finger coloration, respiratory phlegm development, breathlessness, muscle and joint agony, chills, retching, Coughing up blood and looseness of the bowels [21-23]. 


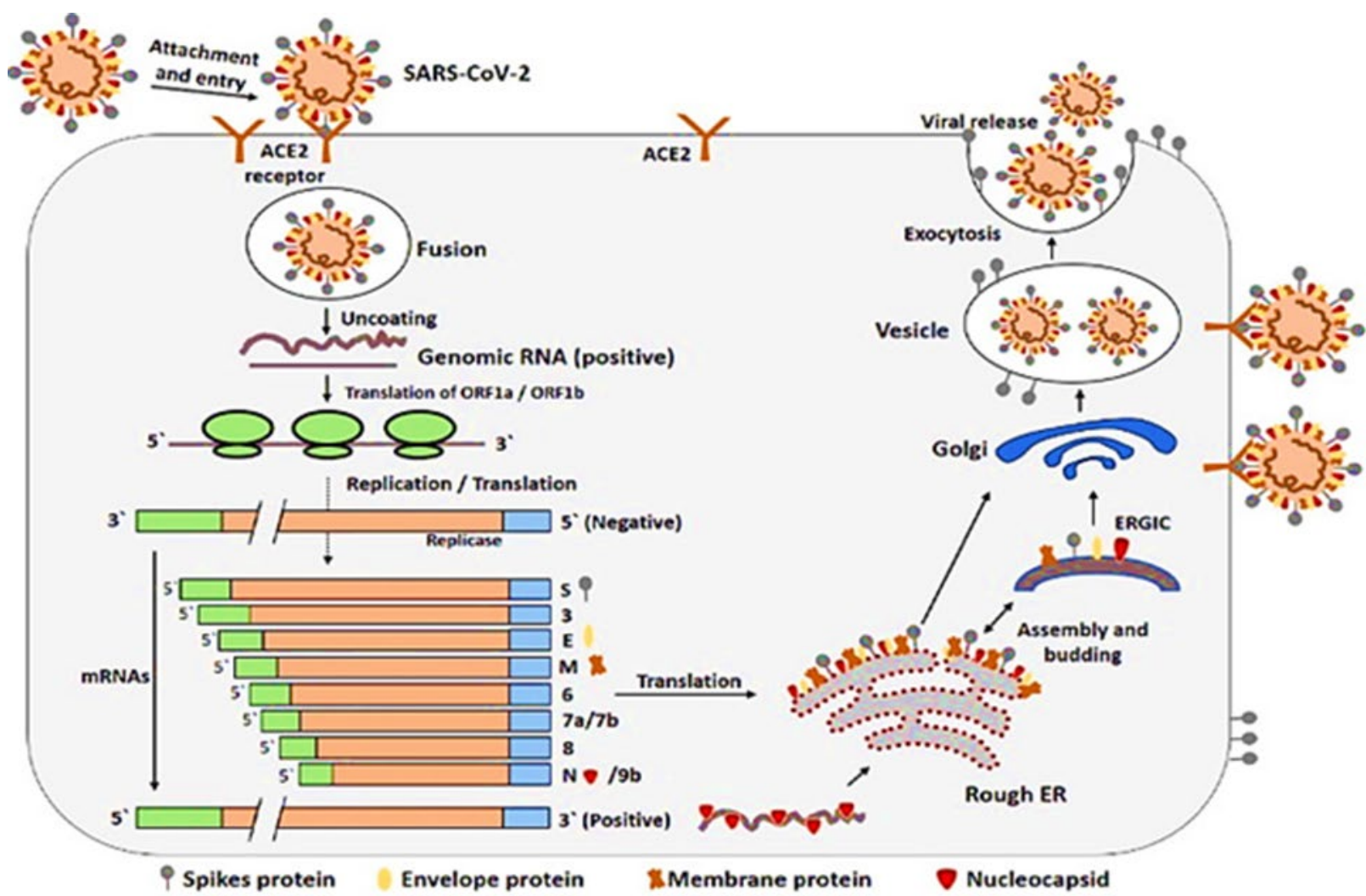

Figure 2. The putative life cycle of SARS-CoV-2 begins its life cycle by binding S protein to the ACE2 cellular receptor. The conformation change in the $S$ protein facilitates viral envelope fusion with the cell membrane via the endosomal pathway following binding of the receptor. SARS would then release RNA into host cell. Genome RNA is translated into viral replicase polyproteins pp1a and 1ab which viral proteinases then cleave into small, products. A series of subgenomic mRNAs are formed by polymerase through discontinuous transcription and finally translated into specific viral proteins. Subsequently, viral proteins and genome RNA are assembled into ER and Golgi virions and then transported via vesicles and released out of the cell. ACE2, enzyme synthesis of angiotensin 2; ER, reticulum endoplasm; ERGIC, intermediate compartment ER - Golgi; The replicated virions are released from the cell to infect other cells by exocytosis [11,14-16]

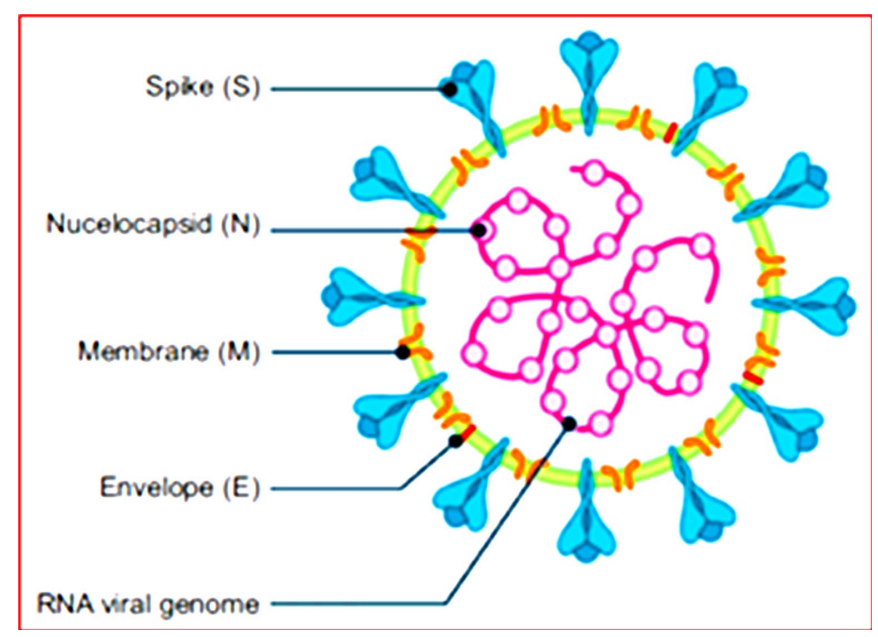

Figure 3. Coronavirus structure

\section{Serious symptoms}

Almost one in five people develop chronic illness and experience difficulty breathing, chest problem and stress. The development of the disease may result in conceivably deadly difficulties such as renal failure, lung injury, sepsis, septic stroke, loss of movement and discourse requiring hospitalization $[7,24]$. There are infected people who are carriers of the virus and have no clinical signs, but the viral infection test is positive. This carrier may be transmitted before symptoms develop [25].

\section{Asymptomatic Infection}

COVID-19 is mainly transmitted by respiratory drops that are expelled by an infected person. It can be found in a person who appears to have moderate cough and does not feel sick, as several studies and research have reported SARS-CoV-2 infections that had no signs, and also in sick peoples who had no previous signs. Because people without symptoms are not routinely tried, the prevalence of virus without symptoms and the identification of infections before symptoms are not well known [26-28]. One investigation indicated that about $13 \%$ of affirmed instances of RT-PCR for SARS-CoV- 2 disease in youngsters were asymptomatic [26]. Whereas other study found residents of CoV-2 health care settings that at the time of monitoring and testing, half of the incidents were not accompanied by symptoms. Patients 
may have problems with imaging the chest before symptoms develop [29,30].

\section{COVID-19 Symptoms vs. Signs of Other Respiratory Ailments}

The manifestations of COVID-19 are fundamentally the same as other respiratory ailments, for example, the normal cold, flu or influenza, and occasional hypersensitivities, however a significant distinction between COVID-19, colds, and influenza is that it causes brevity of breath. The normal cold or influenza intensifies the state of individuals with asthma, as their breath strait, and sensitivity causes some manifestations like the effects by COVID-19, however they once in a while cause coughing dry and don't cause fever [31-33].

The primary manifestations of COVID-19 are fever, cough, brevity of breath. Some COVID-19 patients may likewise some of the time show different signs, for example, sore throat, cerebral pains, nausea, weariness or tiredness, body hurts and diarrhea. The most ideal approach to shield yourself from getting tainted is by standard and appropriate handwashing, keeping away from enormous crowds, and deferring trivial travel to zones with known neighborhood COVID-19 transmission [34-36].

\section{Symptoms of the Flu}

Flu or influenza is a seasonal sickness. It is brought about by three kinds of flu infections and has a few unique strains. Like COVID-19, influenza is infectious and can spread quickly from individual to individual. Manifestations of the flu include fever or feeling hot and having chills, cough, cerebral pains, sore throat, runny or stodgy nose, muscle and headaches, tiredness, spewing [uncommon] and vomiting [uncommon]. The most ideal approach to shield yourself from getting this season's flu virus is to ensure you get the yearly influenza immunization. Ensure kids additionally get the total suggested vaccinations [37-40].

\section{Symptoms of the Common Cold}

Like COVID-19 and seasonal influenza, the regular virus is brought about by infections effectively got through direct contact. It has same symptoms as this season's flu virus but milder, and they normally progress progressively. These include sneezing, runny or stodgy nose, slight body pains, sore throat, mellow to moderate chest uneasiness, weakness or tiredness [sometimes], fever or chills [uncommon], migraines [uncommon]. The most ideal approach to battle colds is to get a lot of rest and drink a lot of liquids. Colds by and large do not cause genuine medical issues and resolves itself in around fourteen days, even without treatment [3335].

\section{Symptoms of Allergic Rhinitis}

The American College of Allergy, Asthma and Immunology [ACAAI] characterizes allergic rhinitis as a hypersensitive response to airborne allergens, for example, the seasonal dusts or pollens and animal dander. It shares numerous manifestations as a typical cold, yet it is not brought about by an infection. Symptoms of hypersensitive rhinitis, include stodgy nose because of blockage or clog, sneezing, itching in the nose, mouth, eyes, or throat, cough and swollen eyelids Allergic rhinitis is generally inherited in the family. Hypersensitivity bouts are frequently ordinarily activated by tobacco smoke, items with strong scents [e.g., fragrances, beautifying agents, hair spray], clothing cleansers, cleaning arrangements, pool chlorine, vehicle exhaust, and other air pollutants. Most occurrences are moderately fleeting, with indications improving in three to seven days. Sneezing and nasal congestion are common in seasonal allergies, but there is rarely a sneezing or runny nose with coronavirus. Coronavirus usually occurs in cough, but seasonal allergies are rare unless your allergies cause asthma. You will not have hypersensitivity fever, which is regular in coronavirus, and you will not get body a throbbing painfulness or diarrhea either. Researchers cannot easily cultivate human coronavirus in the lab not like the nasal virus, which is another reason for a typical virus. This makes it hard to measure the impact of coronavirus on national economies and general health. The doctor can determine the virus responsible in a sample of fluids from a person's body, such as a sample of blood or mucus fluid from the nose.

There is no vaccine presently accessible for COVID-19. In any case, researchers have now repeated the virus. This may permit early discovery and treatment in individuals who have the infection however do not experience symptoms. For correlation between the symptoms of COVID-19 and different symptoms of ailment, it very well may be shown in the accompanying (Table 1) $[1,4,18]$.

\section{Risk Group or Population for Serious COVID-19}

The following populations are more likely to experience more severe complications of COVID disease according to the Centers for Disease Control and Prevention (CDC)

- People 65 years of age or older living in nursing homes, age is a strong risk factor for extreme disease, difficulties and demise, among in excess of 44,000 affirmed instances of COVID-19 in China, the case death rate was higher among the old $[2,8,41,42]$. 
Table 1. Comparison between the symptoms of cold, flu, seasonal allergies and COVID-19

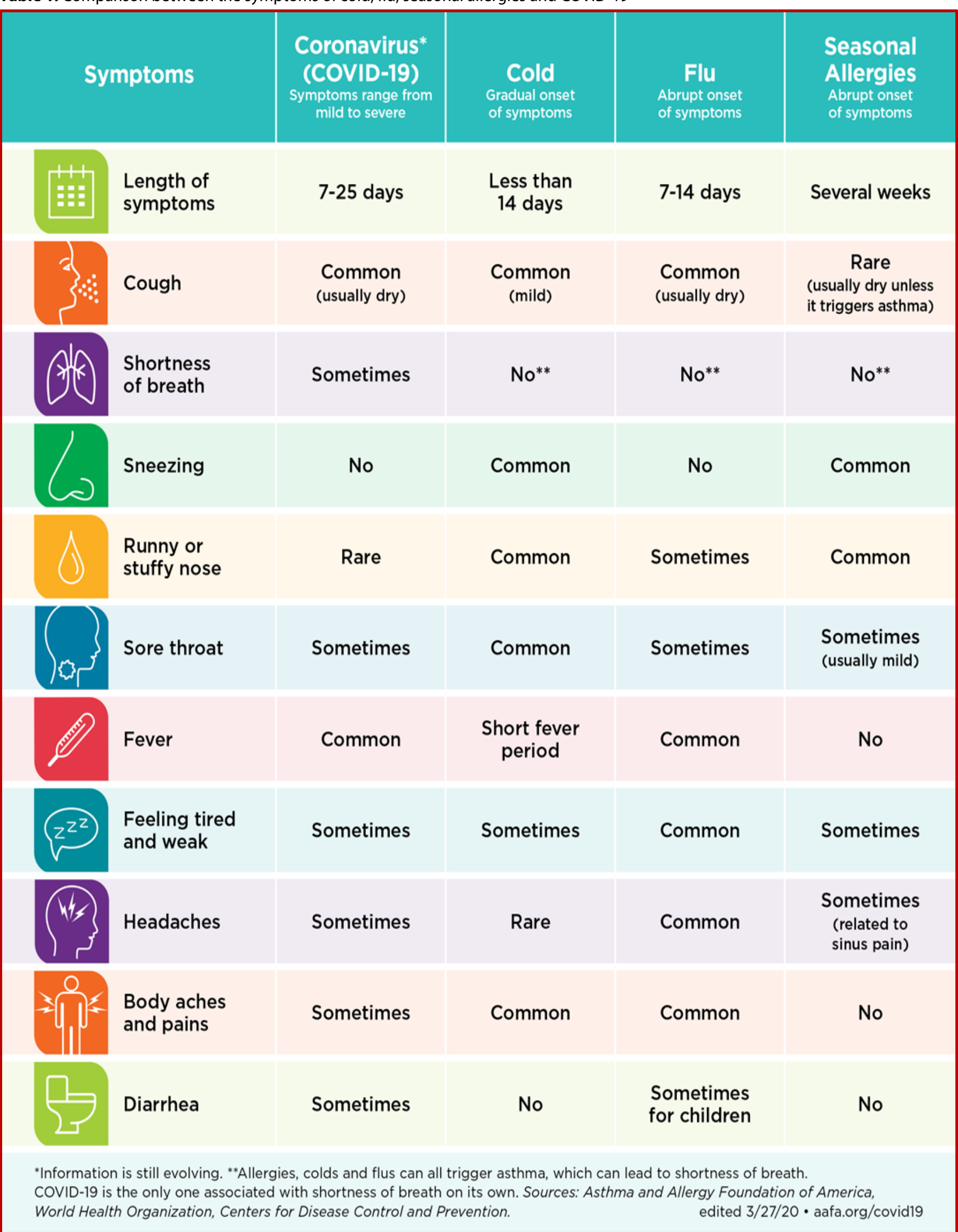


- People with fundamental medical issues, for example, hypertension, lung and heart issues, diabetes, or malignancy, constant lung sicknesses, weakened immune systems, and ceaseless kidney malady $[8,43,44]$.

- Pregnant ladies [women] are bound to cause serious illness when they are affected by infections of the same family as [those that cause COVID-19 and other viral respiratory diseases. In addition, the $\mathrm{CDC}$ prescribes that children born to suspected or certain COVID-19 women should be isolated.

Where the World Health Organization demonstrates that the two gatherings most in danger of creating serious illness because of SARS-CoV-2 are the older individuals and individuals with other wellbeing conditions that endanger their immune system. Numerous authors have observed that the clinical signs of COVID-19 in kids are equivalent to adults and are typically milder contrasted with grown-ups, where the CDC takes note of that in spite of the fact that complications are documented in young children, they are uncommon. COVID-19 generates minor symptoms typically in babies. However, anyone can catch COVID-19 with serious illness $[8,43]$.

\section{Serological Test by CDC}

It is an ELISA-based test external symbol to recognize SARSCoV-2 antibodies in serum or plasma blood segments. It uses refined SARS-CoV-2 $S$ protein (no live infection) as an antigen (structured by the Vaccine Research Center external symbol of the National Institutes of Health).The results of the antibody test are particularly significant for the identification of past diseases in individuals who have had little or no indication [23,33,34].

\section{Emergency Medical Attention Consideration}

When searching for crisis notice signs for COVID-19, and on the off chance that somebody gives any of these indications, crisis medical consideration ought to be looked for right away. Individuals of any age who have a fever and /or cough related with breathing trouble/brevity of breath, chest torment/pressure, discourse misfortune ought to promptly take clinical consideration. It is ideal to contact the healthcare provider or office first, so the patient can be coordinated to the proper clinic $[1,5,29]$.

\section{Most Significant Measures to be Taken to Keep Away from Infection}

Making strides, for example, hand washing, surface cleaning, face covers and respiratory cleanliness, physical prohibition, can assist individuals with ensuring themselves as well as other people. Take enough rest and maintain a strategic distance, drink an excessive amount of water, abstain from smoking and avoid smoky territories, and take acetaminophen [Tylenol] to spare pain, and decrease fever with a clean cream or a cold shower evaporator $[7,22,23]$.

\section{CONCLUSION}

As of late, the advancement of corona infections, which causes a wide scope of human sicknesses, has prompted enormous flare-ups because of their capacity to reconfigure, change and contaminate numerous sorts of cells. It is important to bear in mind that the correct diagnosis of COVID-19 is not only clinical, but rather by examining a sample from the nose or mouth in a laboratory. In some cases, it might be hard to figure out what disease you might be encountering. The manifestations of COVID-19 are like those of other respiratory ailments, for example, colds, influenza, and occasional hypersensitivities, however a significant distinction between COVID-19, colds, and influenza is that it causes brevity of breath. The normal cold or influenza intensifies the state of individuals with asthma, as their breath strait, and sensitivity causes some manifestations like the effects by COVID-19, however they once in a while cause coughing dry and don't cause fever.

\section{DECLARATION OF CONFLICT OF INTEREST}

The authors received no financial support for the research and/or authorship of this article. There is no conflict of interest.

\section{REFERENCES}

1. WHO. Novel Corona virus, China. WHO. Available at: https://www.who.int/csr/don/12-january2020-novelcoronavirus-china/en/ (Accessed: 9 April 2020).

2. Huang C, Wang Y, Li X, Ren L, Zhao J, Hu Y, et al. Clinical features of patients infected with 2019 novel coronavirus in Wuhan, China. Lancet, February 2020; 395(10223): 497-506.

3. Statement on the second meeting of the International Health Regulations. Emergency Committee regarding the outbreak of novel coronavirus 2019 -nCoV. World Health Organization. 30 January 2020. Archived from the original on 31 January 2020.

4. WHO Director- General's opening remarks at the media briefing on COVID-19. World Health Organization. 11 March 2020. Available at: https://www.who.int/dg/speec hes/detail/who-director-general-s-opening-remarks-atthe-media-briefing-on-covid-19---11-march-2020 
5. COVID-19 Educational Disruption and Response. UNESCO. 4 March 2020.

6. Lauer SA, Grantz KH, Bi Q, et al. The Incubation Period of Coronavirus Disease 2019 (COVID-19) From Publicly Reported Confirmed Cases: Estimation and Application. Annals of internal medicine, 2020; 172(9): 577-82. (10.7326/M20-0504).

7. Questions \& Answers (Q\&A) on coronaviruses. World Health Organization. 8 April 2020. Available at: https://www.who.int/

8. Guan WJ, Ni ZY, Hu Y, et al. Clinical Characteristics of Coronavirus Disease 2019 in China. The New England journal of medicine, 2020; 382: 1708-20. (doi: 10.1056/NEJMoa2002032).

9. Hanley B, Lucas SB, Youd E, Swift B, Osborn M. Autopsy in suspected COVID-19 cases. J Clin Pathol. 2020; 20: 206522. (doi: 10.1136/jclinpath-2020-206522).

10. Huang C, Wang Y, Li X, Ren L, Zhao J, Hu Y, et al. Clinical features of patients infected with 2019 novel coronavirus in Wuhan. China Lancet, 2020; 395(10223): 497-506. (doi: 10.1016/S0140-6736(20)30183-5).

11. Lei J, Li J, Li X, Qi X. CT imaging of the 2019 novel coronavirus (2019-nCoV) pneumonia, Radiology, 2020: 200236. (doi: 10.1148/radiol. 2020200236).

12. Di Gennaro F, Pizzol D, Marotta C, Antunes M, Racalbuto V, Veronese N. Coronavirus Diseases (COVID-19) current status and future perspectives: A narrative review. Inter J Enviro Res Pub Heal. 2020; 17(8): 2690. (doi: 10.3390/ijerph17082690).

13. Carcillo JA, Shakoory B. Cytokine storm and sepsisinduced multiple organ dysfunction syndrome. Cytok Storm Synd. 2019: 451-64. (doi: 10.1007/978-3-03022094-5_27).

14. Du Toit A. Outbreak of a novel coronavirus. Nat. Rev. Microbiol., 2020; 18: 123. (doi: 10.1038/s41579-020-0332$0)$.

15. Wu F, Zhao S, Yu B, Chen Y-M, Wang W, et al. A new coronavirus associated with human respiratory disease in China. Nature, 2020: 579: 265-9.

16. Wan Y, Shang J, Graham R, Baric RS, Li F. Receptor recognition by novel coronavirus from Wuhan: an analysis based on decade-long structural studies of SARS Coronavirus. J Virol, 2020; 94: e00127-20. (doi: 10.1128/JVI.00127-20).
17. Chen N, Zhou M, Dong X, et al. Epidemiological and clinical characteristics of 99 cases of 2019 novel coronavirus pneumonia in Wuhan, China: a descriptive study. Lancet, 2020; 395(10223): 507-13. (doi: 10.1016/S0140-6736(20)30211-7).

18. Coronavirus Disease 2019 COVID-19-Symptoms. Centers for Disease Control and Prevention. 20 March 2020. Available at: https://www.cdc.gov/coronavirus/2019ncov/symptoms testing/symptoms.html

19. Yang Y, Lu Q, Liu M, Wang Y, Zhang A, et al. Epidemiological and clinical features of 2019 novel coronavirus outbreak in China. medRxiv, 2020. (doi: 2020.02.10.20021675).

20. Wang D, Hu B, Hu C. Clinical Characteristics of 138 Hospitalized Patients with 2019 Novel CoronavirusInfected Pneumonia in Wuhan, China. JAMA, 2020; 323(11): 1061-9. (doi: 10.1001/jama.2020.1585).

21. Novel Coronavirus Pneumonia Emergency Response Epidemiology Team. The epidemiological characteristics of an outbreak of 2019 novel coronavirus diseases (COVID-19) in China. Zhonghua Liu Xing Bing Xue Za Zhi, 2020; $41(2):$ 145-51.

22. Coronavirus. World Health Organization. Available at: https://covid19.who.int/

23. CDC (11 February 2020). Coronavirus Disease 2019 (COVID-19). Centers for Disease Control and Prevention.

24. Interim Clinical Guidance for Management of Patients with Confirmed Coronavirus Disease [COVID-19]. Centers for Disease Control and Prevention. 4 April 2020. Available at: https://www.winfocus.org/interim-clinicalguidance-for-management-of-patients-with-confirmedcoronavirus-disease-covid-19/

25. Arons MM, Hatfield KM, Reddy SC, Kimball A, James A, Jacobs JR, et al. [April 2020]. Presymptomatic SARS-CoV2 Infections and Transmission in a Skilled Nursing Facility. The New England Journal of Medicine, 2020; 382-208190. (doi: 10.1056/NEJMoa2008457).

26. Dong Y, Mo X, Hu Y, et al. Epidemiological Characteristics of 2143 Pediatric Patients With 2019 Coronavirus Disease in China. Pediatrics, 2020; 58(4): 712-3. (doi: 10.1542/peds.2020-0702).

27. Lu X, Zhang L, Du H, et al. SARS-CoV-2 Infection in Children. The New England journal of medicine, 2020; 382: 1663-5. (doi: 10.1056/NEJMc2005073). 
28. Pan X, Chen D, Xia Y, et al. Asymptomatic cases in a family cluster with SARS-CoV-2 infection. The Lancet Infectious diseases, 2020;20(4):410-1. (doi: 10.1016/S1473-3099(20) 30114-6).

29. Hu Z, Song C, Xu C, et al. Clinical characteristics of 24 asymptomatic infections with COVID-19 screened among close contacts in Nanjing, China. Science China Life sciences, 2020; 63(5): 706-11. (doi: 10.1007/s11427020-1661-4).

30. Wang Y, Liu Y, Liu L, Wang X, Luo N, Ling L. Clinical outcome of 55 asymptomatic cases at the time of hospital admission infected with SARS-Coronavirus- 2 in Shenzhen, China. The Journal of infectious diseases, 2020; 221(11): 1770-4. (doi: 10.1093/infdis/jiaa119).

31. COVID-19 Dashboard by the Center for Systems Science and Engineering (CSSE) at Johns Hopkins University (JHU)". ArcGIS. Johns Hopkins University. Available at: https://gisanddata.maps.arcgis.com/apps/opsdashboar d/index.html\#/bda7594740fd40299423467b48e9ecf6 (Accessed: 12 May 2020).

32. Borunda D. Coronavirus: Fort Bliss stops releasing numbers of COVID-19 cases after Pentagon order. EI Paso Times, 1 April 2020. Available at: https://www.Icsunnews.com/story/news/military/ft-bliss/2020/04/01/fortbliss-stops-releasing-numbers-covid-19-coronaviruscases/5104073002/

33. CDC (11 February 2020). Coronavirus Disease 2019 (COVID-19). Centers for Disease Control and Prevention.

34. CDC (23 April 2020). Coronavirus Disease 2019 (COVID19) in the U.S. Centers for Disease Control and Prevention. Available at: https://www.cdc.gov/ coronavirus/2019-ncov/cases-updates/cases-in-us.html (Accessed: 24 April 2020).

35. CDC (11 February 2020). Coronavirus Disease 2019 (COVID-19). Centers for Disease Control and Prevention. Available at: https://www.cdc.gov/coronavirus/2019-nc ov/hcp/ending-isolation.html (Accessed: 24 April 2020).
36. Questions \& Answers (Q\&A) on coronaviruses. World Health Organization. 8 April 2020. Available at: https://www.who.int/

37. World Health Organization (WHO). (2020). Q\&A on coronaviruses (COVID-19). Available at: https://www. who.int/news-oom/q-a-detail/q-a-coronaviruses

38. Pan American Health Organization (PAHO). (2020). Similarities and differences - COVID-19 and influenza. Available at: https://www.paho.org/hq/index.php? option=com_content\&view=article\&id=15760:similariti es-and-differences-covid-19-and-influenza\&catid=740\& lang=en\&ltemid $=1926$

39. Johns Hopkins Medicine. (2020). Coronavirus Disease 2019 vs. the Flu. Available at: https://www.hopkins medicine.org/health/conditions-and-diseases/corona virus/coronavirus-disease-2019-vs-the-flu

40. World Health Organization (WHO). (2020). Q\&A: Similarities and differences COVID-19 and influenza. Sources: World Health Organization, Centers for Disease Control and Prevention.

41. Wu C, Chen X, Cai Y, et al. Risk Factors Associated with Acute Respiratory Distress Syndrome and Death in Patients with Coronavirus Disease 2019 Pneumonia in Wuhan, China. JAMA Intern Med, 2020; 180(7): 934-43. (doi: 10.1001/jamainternmed.2020.0994).

42. Livingston E, Bucher K. Coronavirus Disease 2019 (COVID-19) in Italy. Jama, 2020; 323(14): 1335. (doi: 10.1001/jama.2020.4344).

43. Zhou F, Yu T, Du R, et al. Clinical course and risk factors for mortality of adult inpatients with COVID-19 in Wuhan, China: a retrospective cohort study. Lancet, 2020; 395(10229): 1054-62. (doi: 10.1016/S01406736(20)30566-3). 